\title{
Clouds or Sunshine in Katowice? Transparency in the Paris Agreement Rulebook
}

\author{
Christopher Campbell-Duruflé*
}

This article identifies outstanding issues regarding the adoption of MPGs for the transparency framework of the Paris Agreement at the Conference of the Parties in Katowice in December 2018. The article first offers a definition of the concept of transparency, and reviews certain salient elements in the literature. This includes a warning that adopting transparency rules that elude questions of accountability of Parties for their domestic policies and equity in burden sharing may fail the objective of building the trust and confidence for which the transparency framework was adopted. The article next offers a brief overview of the requirements of Article 13 of the Paris Agreement, before assessing three key matters raised by the August 2018 draft of the MPGs in light of the literature and recent submissions by Parties. The article underscores the relevance of including a focus on ex ante accountability for climate policies in the way the transparency framework is set to operate, in view of the overall focus of the Paris Agreement on prevention of environmental harm. Comparing the potential of transparency rules to promote accountability of reporting and accountability of implementation of Parties' commitments, it further argues for the inclusion of both foci in the modalities. Lastly, the article highlights that the Paris Rulebook presents a unique opportunity to craft specific roles for non-Party stakeholders in the operation of the transparency framework, thereby developing the links between the United Nations Framework Convention on Climate Change and transnational climate governance initiatives.

\section{Introduction}

The Parties to the 2015 Paris Agreement decided that their Conference of the Parties (CMA) would adopt the modalities, procedures and guidelines (MPGs) for the implementation of the new treaty's transparency framework by the end of its first session. ${ }^{1}$ Because of the amount of work necessary for the completion

DOI: $10.21552 /$ cclr/2018/3/7

* Christopher Campbell-Duruflé, SJD Candidate and Pierre Elliott Trudeau Foundation Scholar 2016, University of Toronto. For correspondence: <c.campbell.durufle@mail.utoronto.ca>. I am indebted to Professors Harro van Asselt and Michael Mehling for their helpful comments on this article.

1 Paris Agreement (adopted 12 December 2015, entered into force 4 November 2016) 55 ILM 740 art 13.

2 UNFCCC 'Decision 1/CP.21, Adoption of the Paris Agreement' UN Doc FCCC/CP/2015/10/Add.1 (29 January 2016) paras 92-99.

3 United Nations Framework Convention on Climate Change (adopted 9 May 1992, entered into force 21 March 1994) 1771 UNTS 107. of this task, which forms part of what is known as the Paris Rulebook, the first session of the CMA was extended until the UNFCCC's $24^{\text {th }}$ Conference of the Parties (COP 24) in 2018. The Parties also delegated the critical task of preparing the MPGs for the transparency framework to the Ad Hoc Working Group on the Paris Agreement (APA), ${ }^{2}$ which has met six times since COP 21 and has one last meeting planned to complete its work in December 2018 in Katowice, Poland.

This short article identifies three important issues that stand before Parties for resolution regarding the MPGs of the transparency framework. In Section 2, I start by offering a definition of the principle of transparency, based on a brief overview of international law scholarship. In Section 3, I provide an outline of Article 13 of the Paris Agreement, and contrast it with pre-existing reporting processes under the United $\mathrm{Na}$ tions Framework Convention on Climate Change (UNFCCC). ${ }^{3}$ Lastly, in Section 4, I assess the August 
2018 draft of the MPGs prepared by the APA Co-Chairs for Agenda Item $5,{ }^{4}$ released as a result of the work at their meeting in Bonn, Germany in May 2018. A sense of urgency is palpable in the draft conclusions released by the Co-Chairs, who write that 'work needs to be accelerated across all items [...] to ensure that all issues achieve the degree of maturity and detail needed to fully operationalize the Paris Agreement'. ${ }^{5}$

Specifically, I first show the relevance of including a focus on ex ante accountability for climate policies in the way the transparency framework is set to operate, in view of the overall focus of the Paris Agreement on prevention of environmental harm. Second, I compare the potential of transparency rules to promote accountability of reporting and accountability of implementation of Parties' commitments, and I argue for the inclusion of both foci in the MPGs. Third, I highlight that the Paris Rulebook presents a unique opportunity to craft specific roles for non-Party stakeholders in the operation of the transparency framework.

\section{Transparency: Clouds or Sunshine?}

I start by reviewing a brief selection of international law scholarship on the principle of transparency. Interestingly, authors have both noted the potential of transparency-oriented provisions to illuminate and to obscure global environmental issues. This cautionary note is of high relevance to the ongoing efforts to design MPGs that 'build mutual trust and confidence and [...] promote effective implementation,' rather than cynicism or indifference.

Weiss and Jacobson, for example, situate transparency as an approach to promoting compliance within the broader category of 'sunshine methods', understood as those 'intended to bring behavior of parties [to a multilateral environmental agreement (MEA)] and targeted actors into the open for appropriate scrutiny, and thereby to encourage compliance'. These can take a variety of forms, including national reporting, scrutiny of reports, on-site monitoring, and access to information by non-governmental organisations (NGOs). Both authors also identify a variety of factors that will influence whether compliance will in fact be induced, including the sensitivity of the Party in question to its reputation, whether there exists a culture of compliance, capacity and access to the resources necessary to engage in reporting, and the degree of involvement of civil society and the business sector. ${ }^{8}$

In the context of the application of MEAs, Brunnée and Hey argue that the notion of transparency can be subdivided in two: transparency of governance and transparency for governance. While the former refers to the degree to which the activities and decisions of an international organisation are accessible to stakeholders, the former is of greater interest for the present purpose. Transparency for governance is understood as comprising the policy instruments deployed by an [international environmental institution], used in support or in lieu of regulation, to influence the conduct of States and non-State actors. ${ }^{9}$ In the climate regime specifically, Brunnée and Hey argue that transparency has played a central role in fostering 'common understandings of what it would take to meet the regime's objective', providing a clear picture of the baseline for the negotiations, building trust among Parties that their performance will be matched by that of others, monitoring implementation, and determining what role should be exercised by third parties (such as treaty secretariats and the private sector).$^{10}$ In this sense, if one understands legality as a characteristic of norms that flows both from social interactions between international actors and from respect of certain agreed-upon formal criteria, transparency for governance can even be considered as a precondition for 'governance anchored in law.'11

4 This article was written before the September 2018 meeting of the APA in Bangkok, Thailand. See: UNFCCC 'Additional Tool under item 5 of the Agenda, Modalities, Procedures and Guidelines for the Transparency Framework for Action and Support Referred to in Art 13 of the Paris Agreement, Informal Document by the CoChairs' UN Doc AP A1.6.Informal.1.Add.3 (3 August 2018) (Draft MPGs).

5 UNFCCC 'Agenda Items 3-8, Draft Conclusions Proposed by the Co-Chairs' UN Doc FCCC/APA/2018/L.2 (10 May 2018) para 3.

6 Paris Agreement (n 1) art 13(1).

7 Edith Brown Weiss and Harold K. Jacobson, 'Assessing the Record and Designing Strategies to Engage Countries' in Edith Brown Weiss and Harold K. Jacobson (eds), Engaging Countries: Strengthening Compliance with International Environmental Accords (MIT Press 1998) 543.

8 ibid 543-546.

9 Jutta Brunnée and Ellen Hey, 'Transparency and International Environmental Institutions' in Andrea Bianchi and Anne Peters (eds), Transparency in International Law (Cambridge University Press 2013) 23, 47.

10 ibid 38-39.

11 ibid 29. See also: Jutta Brunnée and Stephen I Toope, Legitimacy and Legality in International Law: An Interactional Account (Cambridge University Press 2010). 
More specifically in the context of the climate regime, Gupta and van Asselt warn that the effects of transparency mechanisms on compliance 'are inextricably tied up with (and mirror) first-order conflicts over the scope of accountability and burden sharing' with regard to adaptation and mitigation. ${ }^{12}$ To the extent that the approach to accountability adopted in the climate regime eludes answerability of Parties for their domestic policies and some form of enforceability at the outcome of the accountability process, they warn, it is unlikely that transparency will promote favourable environmental outcomes. They argue that transparency-oriented provisions that focus on capacity-building to enable developing countries to participate in increasingly elaborate reporting and review schemes, instead of shining light on issues of ambition and fairness, 'might even distract from the search for more far-reaching accountability in this global context.' ${ }^{13}$ In this sense, as Bianchi has warned, the mere sharing of information does not amount to transparency in and of itself and may be instrumentalised for many purposes, thereby more akin to a

12 Aarti Gupta and Harro van Asselt, 'Transparency in Multilateral Climate Politics: Furthering (or Distracting From) Accountability?' $(2017$, fc) Reg \& Gov 14. See also Aarti Gupta and Michael Mason, 'Disclosing or Obscuring? The Politics of Transparency in Global Climate Governance' (2016) 18 Current Opinion in Environmental Sustainability 90; and Michael Mason, 'Transparency for Whom?: Information Disclosure and Power in Global Environmental Governance' (2008) 8(2) Global Envtl Pol 8.

13 Gupta and van Asselt (n 14).

14 Andrea Bianchi, 'On Power and Illusion: The Concept of Transparency in International Law' in Bianchi and Peters (n 11) 1, 15.

15 Daniel Bodansky, 'The Paris Climate Change Agreement: A New Hope?' (2016) 110(2) AJIL 288, 311.

16 Anne-Sophie Tabau, 'Evaluation of the Paris Climate Agreement According to a Global Standard of Transparency' (2016) 10(1) CCLR 23, 30 .

17 Kyoto Protocol to the United Nations Framework Convention on Climate Change (adopted 11 December 1997, entered into force 16 February 2005) 2303 UNTS 162.

18 UNFCCC 'Decision 1/CP.16, The Cancun Agreements: Outcome of the work of the Ad Hoc WorkingGroup on Long-term Cooperative Action under the Convention' UN Doc FCCC/CP/2010/7/Add.1 (15 March 2011) para 40ff. See also UNFCCC 'Decision 2/CP.17, Outcome of the Work of the Ad Hoc Working Group on Longterm Cooperative Action under the Convention' UN Doc FCCC/CP/2011/9/Add.1 (15 March 2012) para 23-31.

19 Paris Agreement (n 1) art 13(7). The information to be submitted to facilitate clarity, transparency and understanding of progress on intended NDCs had already been discussed in the Lima Call for Climate Action. See UNFCCC 'Decision 1/CP.20, Call for Climate Action' UN Doc FCCC/CP/2014/10/Add.1 (2 February 2015) para 14.

20 Paris Agreement (n 1) art 13(9).

21 ibid art 13(5).

22 ibid art 13(11) mirror for the expectations of those in power than to a clean window that welcomes the public's gaze. ${ }^{14}$

\section{Article 13: Framework for Transparency of Action and Support}

Article 13 of the Paris Agreement establishes a framework for transparency of action on climate change and support to developing country Parties. The strength of this approach to implementation is essential for, as Bodansky notes, 'the Paris Agreement's transparency framework is the main mechanism to hold states accountable' for the realisation of their nationally determined contributions (NDCs) and, ultimately, for the achievement of the UNFCCC's overall objective. ${ }^{15}$ Tabau has argued that this mechanism can even be considered as the 'raison d'être' of the new treaty, because it complements the self-determined nature of the NDCs with some element of external supervision. ${ }^{16}$ In this section, I outline the content of Article 13 and succinctly contrast it with preexisting reporting and review processes under the UNFCCC, the Kyoto Protocol ${ }^{17}$ and the Cancun Agreements. ${ }^{18}$

Under the transparency framework, all Parties are required to provide biennial communications that must contain the following: (1) a national inventory report of greenhouse gas emissions by sources and removals by sinks, prepared using good practice methodologies accepted by the Intergovernmental Panel on Climate Change (IPCC); and (2) information necessary to track progress in implementing and achieving NDCs. ${ }^{19}$ Furthermore, developed country Parties shall provide information regarding their financial, technology transfer, and capacity-building support measures. ${ }^{20}$ This requirement is optional for developing countries that also provide support.

Furthermore, two processes must be fleshed out in the Paris Rulebook in a way that aims at providing a clear understanding of the information submitted and identifying good practices, priorities, needs and gaps. ${ }^{21}$ First, the information presented under Article 13, paragraphs 7 and 9 will be subject to a Technical Expert Review (TER). This process is aimed at assessing the consistency of the information presented with the MPGs currently under negotiation and identifying 'areas of improvement'. ${ }^{22}$ It should show flexibility towards developing countries and pay particular attention to their respective national 
capabilities and circumstances. ${ }^{23}$ Second, a process called Facilitative Multilateral Consideration of Progress (FMCP) will be conducted with the objective of assessing advances in the implementation of NDCs and the provision of financial support to developing countries for both mitigation and adaptation under Article $9 .{ }^{24}$ The description of this process is limited, and leaves it to the APA to design this new forum for engagement by Parties and possibly nonParty stakeholders (NPS) with the information reported and the conclusions of the TER.

The COP decision adopting the Paris Agreement indicates that the MPGs will 'build upon and eventually supersede' pre-existing transparency mechanisms under the UNFCCC, and in particular the Cancun Agreements. ${ }^{25}$ This reveals the intention of the Parties to incorporate the accumulated experience with the National Communications and Biennial (Update) Reports, the International Assessment and Review, and the International Consultation and Analysis, among others, in the MPGs. Similarly, under the Kyoto Protocol, signatory Parties have gained experience with annual reports on compliance with assigned greenhouse gas emissions amounts (Article 7). Furthermore, an initial report had to be submitted by Annex I Parties at the commencement of both commitment periods (2008-2012 and 2013-2020) for the purpose of demonstrating their capacity to account for emissions and respect their assigned emission amounts. ${ }^{26}$ Likewise, a so-called true-up period report is due at the end of each commitment period in order to assess Parties' compliance with their respective assigned amounts. ${ }^{27}$

Doelle has observed that building on previous experiences presents potential for 'more regular and comprehensive reporting, a more harmonized verification process, and common MPGs, procedures, and guidelines', while at the same time minimising the burden of compliance for Parties, and in particular developing countries. ${ }^{28}$ On this note, Article 13(2) explicitly links the transparency requirements to the principle of flexibility in view of the different levels of capacity of Parties. The focus on capacity as differentiator is also present in Decision 1/CP.21 and accompanied by the establishment of a CapacityBuilding Initiative for Transparency. ${ }^{29}$ Article 13 does not, however, include the expression 'equity and common but differentiated responsibilities and respective capabilities, in the light of different national circumstances' found elsewhere in the treaty. This rais- es the question of how the MPGs for the transparency framework should incorporate flexibility and whether they should reflect both differences in capacity and responsibilities, an issue to which I return in the following section. ${ }^{30}$

\section{Outstanding Issues for Katowice}

In August 2018, the APA Co-Chairs released a new version of the draft MPGs for the transparency framework, which contains different textual alternatives on all issues where consensus has not yet been reached. This document builds on the informal note prepared by co-facilitators responsible for Agenda Item 5, Xiang Gao (China) and Andrew Rakestraw (United States of America), following the Bonn session of APA 1.5 in May 2018. ${ }^{31}$ The sheer size of this piece of the Paris Rulebook (69 pages) hints at the amount of work left for Parties before the draft MPGs are transmitted to the CMA in Katowice.

In this section, I discuss three outstanding issues that are particularly important for the successful completion of the negotiations on the Paris Rulebook

23 ibid art 13(12).

24 ibid art 13(11).

25 Decision 1/CP.21 (n 2) para 98.

26 See UNFCCC, 'Decision 13/CMP.1, Modalities for the Accounting of Assigned Amounts under Art 4, paragraph 4 of the Kyoto Protocol' UN Doc FCCC/KP/CMP/2005/8/Add.2 (30 March 2006), and UNFCCC, 'Decision 2/CMP.8, Implications of the implementation of decisions 2/CMP.7 to 5/CMP.7 on the previous decisions on methodological issues related to the Kyoto Protocol, including those relating to Arts 5, 7 and 8 of the Kyoto Protocol' UN Doc FCCC/KP/CMP/2012/13/Add.1 (28 February 2013).

27 UNFCCC, 'Decision 3/CMP.10, Date of the completion of the expert review process under Art 8 of the Kyoto Protocol for the first commitment period' UN Doc FCCC/KP/CMP/2014/9/Add.1 (12 December 2014) para 3.

28 Meinhard Doelle, 'The Paris Agreement: Historic Breakthrough or High Stakes Experiment?' (2016) 6 Climate law 1, 15.

29 Decision 1/CP.21 (n 2) paras 85-91.

30 See also Lavanya Rajamani, 'Ambition and Differentiation in the 2015 Paris Agreement: Interpretative Possibilities and Underlying Politics' (2016) 65 ICLQ 1, Christina Voigt and Felipe Ferreira, 'Differentiation in the Paris Agreement' (2016) 6 Clim L 58; and Sandrine Maljean-Dubois, 'The Paris Agreement: A New Step in the Gradual Evolution of Differential Treatment in the Climate Regime?' (2016) 25(2) RECIEL 151.

31 UNFCCC, 'Draft Elements for APA Agenda Item 5, Modalities, Procedures and Guidelines for the Transparency Framework for Action and Support Referred to in Art 13 of the Paris Agreement, Informal Note by the co-facilitators - Final Iteration' (9 May 2018) $<$ https://unfccc.int/sites/default/files/resource/APA\%20item\%205 informal\%20note_final\%20iteration_09052018\%201514.pdf> (Draft MPGs, 9 May 2018) accessed 25 August 2018. 
and the actual implementation of the treaty: (1) the potential of the transparency framework to promote a prospective form of accountability, over and above scrutinising past achievements; (2) the debate on focusing the transparency framework on substantive environmental outcomes, as opposed to reporting requirements only; and (3) the unique opportunity of engaging non-Party stakeholders in the operation of the transparency framework.

\section{Transparency and Ex Ante Accountability}

One outstanding question for the APA is the extent to which the MPGs of the transparency framework will promote a prospective form of accountability, over and above answerability for past achievements and shortcomings. As Curtin and Nollkaemper have noted, transparency may not only promote accountability through its retrospective focus, but also result from processes that are continuous and participative, including standard-setting by those actors affected by a given issue. ${ }^{32}$ Werner notes that the proliferation of non-compliance procedures that have grown parallel to state responsibility mechanisms - including those that rely on reporting and offering of assistance - go beyond 'the restoration of a broken normalcy' occasioned by compliance issues, and seek 'the realization of a common goal through a co- operative effort'. ${ }^{3}$ In this sense, Hey distinguishes 'prior assessment' from 'post-assessment' under MEAs, ${ }^{34}$ something that appears crucial in the framework of multilateral efforts to prevent human interference with the climate system, rather than to hold those responsible once such a misfortune has happened.

32 Deirdre Curtin and André Nollkaemper, 'Conceptualizing Accountability in Public International Law' (2005) 36 Neth YB Intl L 3.

33 Wouter G Werner, 'Responding to the Undesired: State Responsibility, Risk Management and Precaution' (2005) 36 Neth YB Intl L 57,69

34 Ellen Hey, 'Increasing Accountability for the Conservation and Sustainable Use of Biodiversity: An Issue of Transnational Global Character' (1995) 6 Colo J Intl Envtl L \& Pol'y 1, 4.

35 Draft MPGs (n 4) S B.8. Improvement plan, 25.

36 ibid S G3, 63.

37 Draft MPGs, 9 May 2018 (n 31) S C13, 23.

38 Draft MPGs (n 4) S G.3, Scope, 63.

39 ibid S H.6, Summary report content and format, 73.
Several sections of the draft MPGs contain indications that Parties are considering ways to give a forward-looking dimension to the transparency framework. One example is the proposed sections on 'Improvement Plans', which would require Parties to outline the steps that they expect to take to improve transparency, accuracy, completeness, consistency, and comparability (TACCC) of the information contained in their national inventory reports of emissions. ${ }^{35}$ Engagement by the TER with this plan itself would constitute a concrete example of prior assessment, although one textual proposal specifically opposes this possibility. ${ }^{36}$ Similarly, the MPGs contain a proposal for Improvement Plans focusing on planned activities to improve TACCC of the reported information on progress in implementing NDCs. One proposal would have the Improvement Plans discuss how a Party intends to implement the areas of improvement identified by the TER, but the previous mention of expected steps for the 'review and adjustment of $\mathrm{NDCs}^{\prime 37}$ in an earlier version of the MPGs has been removed. Another proposal would have the TER identify 'barriers to implementation' of NDCs and sources of support to overcome these barriers. ${ }^{38}$

The FMCP also presents opportunities for forward-looking engagement with the information provided. The draft MPGs envision a phase of 'question and answer' and a workshop on the different inputs of the process, including the information presented under Article 13, the TER report, and inputs by other Parties and NPS. The discussions held and the written submissions would be made available on the UNFCCC website and recorded in a procedural summary prepared by the Secretariat, which could identify possibilities of collaboration and/or improvements identified during the process. ${ }^{39}$ Both phases of the FMCP thus open the door to future-oriented exchanges on activities pertaining to both reporting TACCC and NDC implementation, subject to Parties' and participants' willingness to recognise this form of prior assessment as part of the scope of the exercise.

Two final issues highlight the complexity of giving a prospective dimension to the MPGs. One is the debate surrounding developed country Parties' biennial communications on projected levels of public climate finance, mandated by Article 9(5) and referenced in Article 13. The debate as to whether to delegate the elaboration of the MPGs on this point to the Subsidiary Body for Implementation ran for so long 
that it significantly pushed back the conclusion of the entire COP $23 \cdot{ }^{40}$ Another is the requirement for Parties to prepare Adaptation Communications under Article 7(10), also referenced in Article 13. As noted by Elliott and others, the multiple purposes of the transparency framework would be better achieved by including in such reports 'both forward-looking and backward-looking information on adaptation as well as contextual elements such as national circumstances and impacts, vulnerabilities, and risks. ${ }^{41}$

This section suggests that the pursuit of prospective accountability through transparency finds a multiplicity of anchors in the current draft MPGs. Given the overall focus of the Paris Agreement on the realisation of a common goal, these avenues could be expanded over the course of the remaining negotiations. Over and above a focus on past individual successes and shortcomings, requiring Parties to explain and justify their future actions may contribute to build common understandings regarding the implementation of the new treaty and greater trust between Parties.

\section{Improvement of Reporting or Improvement of Implementation?}

The preceding section brought to the fore the tension between the distinct but related goals of improving reporting and of improving implementation of climate targets. Article 13(9) mandates the TER to 'identify areas of improvement for the Party', which could apply both to the issues of conformity of the information provided with the applicable MPGs and to that of adequacy of NDC implementation or of support provided in view of the requirements of the Paris Agreement. How the transparency framework should strike a balance between review of procedural and substantive requirements of the new treaty is a complex question currently on Parties' agenda and will likely occupy their attention beyond COP 24.

Gupta and van Asselt warn that the current approach to transparency within the UNFCCC is confined 'to revealing progress made on implementing existing commitments, with virtually no answerability for actual achievement of commitments or whether they reflect ambition or fairness' ${ }^{42}$ Kramarz and Park's note of caution regarding the use of accountability mechanisms concerning global environmental issues goes further along the same line: a fo- cus on functional requirements such as monitoring, compliance and enforcement as ends in themselves may lead to the absence of accountability for those actors that established the goals in the first place, with possible adverse consequences for environmental outcomes. ${ }^{43} \mathrm{~A}$ focus on whether the rules on TACCC are complied with without consideration of environmental outcomes could result in what Stewart has termed 'pervasive structural disregard' of certain issues, generally (although not necessarily), with adverse impacts on the rights and interests of those less powerful actors. ${ }^{44}$

The draft MPGs display the complexity of this issue. The provisions on Adaptation Communications, for example, refer to the question of 'adequacy and effectiveness of support' on two occasions. ${ }^{45}$ The consideration a Party's 'implementation and achievement of its NDC', 'support provided', and 'areas of improvement' is also contemplated under the scope of work for the TER. ${ }^{46}$ Yet, another textual proposal would mandate that the TER 'not review the adequacy of a Party's nationally determined contribution, domestic actions, or support provided, ${ }^{47}$ an exclusion that could be understood as barring review of progress on implementation. Support for this approach has been manifested by the Like-Minded Developing Countries (LMDC) negotiation group, according to which the TER shall be limited to the issues of transparency, completeness, timeliness and adherence to the MPGs, and 'shall refrain from making any political judgment'. ${ }^{48}$ For the Least Devel-

40 UNFCCC 'Decision 12/CP.23, Process to Identify the Information to be Provided by Parties in Accordance with Art 9, Paragraph 5 , of the Paris Agreement, 14th Plenary Meeting 18 November 2017' UN Doc FCCC/CP/2017/11/Add.1 (8 February 2018).

41 Cynthia Elliott and others, 'Designing the Enhanced Transparency Framework: Reporting under the Paris Agreement' (World Resources Institute 2017) 17.

42 Gupta and van Asselt (n 14) 14

43 Teresa Kramarz and Susan Park, 'Accountability in Global Environmental Governance: A Meaningful Tool for Action?' (2016) 16(2) Global Envtl Pol 1, 19.

44 Richard B Stewart, 'Remedying Disregard in Global Regulatory Governance: Accountability, Participation, and Responsiveness' (2014) 108 AJIL 211, 231

45 Draft MPGs (n 4) S D.1, Objectives and Principles, 42 and S D.8 Monitoring and evaluation of adaptation actions and processes, 45.

46 ibid S G.3, Scope, 63.

47 ibid.

48 'LMDC Submission on Modalities, Procedures and Guidelines for the Transparency Framework for Action and Support under the Paris Agreement, Iran' (9 October 2017) paras 48 and 59. 
oped Countries (LDC) group, by contrast, the TER should include a '[f]ocus on individual Party actions,' in order to identify 'country successes and challenges in meeting the objectives of NDCs' and '[ $\mathrm{f}$ ]acilitate advice and knowledge sharing amongst Parties. $^{49}$

The FMCP also shows potential to promote some form of accountability for actual achievements, going beyond strengths and weaknesses in reporting efforts. While there seems to be agreement between Parties that the goals set in the NDCs are beyond discussion within the transparency framework, the FMCP could foster accountability of Parties for the extent to which they have progressed towards reaching these goals. One textual option from the draft MPGs includes an elaborate list of activities on which the FMCP could focus: 'implementation and achievement of [a Party's] nationally determined contribution, including emissions, removals, participation in voluntary cooperation under Article 6, assumptions, conditions, and methodologies related to the attainment of its nationally determined contribution,. ${ }^{50}$ The draft MPGs also indicate that a Par-

49 'Submission by the Federal Democratic Republic of Ethiopia on behalf of the LDC Group on APA Agenda Item 5' (3 November 2017) (LDC Submission).

50 Draft MPGs (n 4) S H.2, Scope, 71.

51 Paris Agreement (n 1) art 4(2).

52 ibid art 13(1).

53 See DW Greig, 'Reciprocity, Proportionality, and the Law of Treaties' (1994) 34 Va J Intl L 295. For an analysis of the same challenge as it applies to the implementation and compliance committee of the Paris Agreement, see: Christopher CampbellDuruflé, 'Accountability or Accounting? Elaboration of the Paris Agreement's Implementation and Compliance Committee at COP 23' (2018) 8 Clim L 1.

54 See for example: Harriet Bulkeley and others, Transnational Climate Change Governance (Cambridge University Press 2014), Thomas Hale and Charles Roger, 'Orchestration and Transnational Climate Governance' (2014) 9(1) Rev Intl Org 59, and Harro van Asselt \& Fariborz Zelli, 'Connect the Dots: Managing the Fragmentation of Global Climate Governance' (2014) 16(2) Environmental Economics and Policy Studies 137

55 Ellen Hey (n 34) 2. See also Asher Alkoby, 'Non-State Actors and the Legitimacy of International Environmental Law' (2003) 3(1) Non-State Actors and International Law 23; and Steve Charnovitz, Nongovernmental Organizations and International Law' (2006) 100(2) AJIL 348.

56 Decision 1/CP.21 (n 2) paras 118 and 134.

57 'Climate change - COP 21 - Press Briefing by Laurent Fabius, Minister of Foreign Affairs and International Development, President of the COP 21, New York (29 June 2015) < http://www .diplomatie.gouv.fr/en/french-foreign-policy/climate/events/article/ climate-change-cop21-press-briefing-by-laurent-fabius-new-york -29-06-15> accessed 25 August 2018. ty may decline to answer a question put to it during the FMCP 'if it believes a written question is outside the scope' of the FMCP. Given the importance of a consistent practice to sustain Parties' sense of legal commitment towards the Paris Agreement, it appears crucial that this last provision is not used in a way that would overly narrow the scope of Parties' interpretation of what the FMCP comprises.

This section suggests that there are some risks associated with excluding a consideration of barriers, successes, and best practices in the attainment of individual NDCs from the scope of work of the TER or of the FMCP. For transparency provisions to encourage compliance with the notion that Parties 'shall pursue domestic mitigation measures, with the aim of achieving the objectives' of their NDC, ${ }^{51}$ some level of scrutiny appears necessary. Likewise, the primary purposes of the transparency framework are to 'build mutual trust and confidence and to promote effective implementation'. ${ }^{52}$ Rather than an intrusion into national sovereignty, it seems that a transparency framework that fosters both improvement of reporting and of implementation would nurture sense that their efforts will be met with reciprocity rather than free-riding. ${ }^{53}$

\section{NPS Participation}

A third significant question that stands before the APA and ultimately the CMA is the degree to which the MPGs will involve non-Party stakeholders in the shining of sunlight on the steps taken by Parties to implement the Paris Agreement. Given the abundance of transnational climate governance initiatives that developed alongside the multilateral regime on the basis of voluntary standards and the collaboration of public and private actors, ${ }^{54}$ the multiple references to NPS in the Paris outcome appear to pursue the aim of making it 'better converge with the realities of international society. ${ }^{55}$ Most notably, Decision 1/CP.21 'welcomes' and 'invites' non-state actors' climate actions, ${ }^{56}$ which were identified by the COP President Laurent Fabius as nothing less than the 'Fourth Pillar' of the new treaty. ${ }^{57}$ Still, Article 13 does not explicitly establish any role for NPS in the operation of the transparency framework, an absence that, as noted by van Asselt, could even be invoked by those Parties resisting their stronger in- 
volvement in the review of all the information to be submitted. ${ }^{58}$

By contrast, several sections of the draft MPGs that define the information that Parties must submit as part of the transparency framework mention NPS, This is the case, for example, with the provision of information on institutional arrangements regarding the involvement of NPS in 'domestic compliance, monitoring, reporting and evaluation of policies' on mitigation. ${ }^{59}$ Another section references reporting on the knowledge generated by stakeholders and their respective roles in capacity-building activities. ${ }^{60}$ Other sections of the draft go one step further to expand on what was agreed to in Article 13 and propose concrete roles, albeit limited, for NPS in the operationalisation of the transparency framework. This includes involving non-state actors in the nomination process of the technical experts for the TER, ${ }^{61}$ the possibility of allowing either 'relevant stakeholders' or only 'registered observers' to submit written questions in the course of the FMCP, ${ }^{62}$ and the unresolved issue of whether stakeholders and observers will be authorised to raise questions or simply to observe during the workshop phase of the FM$\mathrm{CP}^{63}$

Backing for a broad role for NPS can be found in submissions such as that of the LDC group, that also supports offering non-state actors an opportunity to provide feedback on all the documentation submitted by Parties through the transparency framework, direct participation of NPS in the TER process as expert reviewers, and a role for NPS to 'provide inputs' during the FMCP process, over and above the possibility of raising questions. ${ }^{64}$ Similarly, the ArgentinaBrazil-Uruguay group suggests that the online portion of the FMCP be designed so as to 'facilitate communication between Parties and relevant stakeholders. ${ }^{65}$ Most other Parties, however, do not address this issue in their most recent submission.

Dagnet and others press for the adoption of MPGs that institutionalise the participation of NPS in both the TER and the FMCP, as a way to make the transparency framework more effective, adapted to specific country contexts, dynamic and inclusive. ${ }^{66}$ This would constitute a significant advance, since both antecedents for reporting and review under the Cancun Agreements, namely the International Assessment and Review for developed countries and the International Consultation and Analysis for developing countries, contain nothing of the sort. In this context, van Asselt identifies some precedents which may be of use, including the case when a compliance procedure is triggered by an expert review under the Kyoto Protocol, ${ }^{67}$ the consideration of information presented by civil society in the implementation of the Convention on International Trade in Endangered Species of Wild Fauna and Flora, ${ }^{68}$ and throughout the conduct of the Universal Periodic Review by the Human Rights Council. ${ }^{69}$

This section suggests that there is much potential in crafting avenues for the formal involvement of NPS in the transparency framework. On the one hand, non-state actors could bring significant expertise and resources to the pursuit of the framework's goals, including regarding prior-and post-assessment of the information provided by Parties, improvement of TACCC in reporting, and improvement in the implementation of NDCs and other climate policies. On the other hand, creating a role for NPS in the MPGs offers the potential to strengthen the links between transnational climate governance and the UNFCCC, including through a more direct exposure of state Parties' policies to the innovations, experimentations, and best practices developed by non-state and

58 Harro van Asselt, 'The Role of Non-State Actors in Reviewing Ambition, Implementation, and Compliance under the Paris Agreement' (2016) 6:1-2 Clim L 91, 103.

59 Draft MPGs (n 4) S C.6, Mitigation policies and measures, actions, and plans, including those with mitigation co-benefits resulting from adaptation actions, related to the implementation and achievement of an NDC under Art 4, 37.

60 ibid S E.6, Information on capacity-building support provided under Art 11, 53. See also S F.9 on capacity-building support received.

61 ibid S G.6, Technical expert review team and institutional arrangements, 67.

62 ibid S H.4, Format and steps, including events to be convened, the roles of Parties and the secretariat, 71 .

63 ibid 72.

64 LDC Submission (n 49) 17.

65 Views of Brazil, Argentina and Uruguay on APA Agenda Item 5 (16 October 2017), 15.

66 Yamide Dagnet and others, 'Designing the Enhanced Transparency Framework, Part 2: Review under the Paris Agreement' (World Resources Institute 2017) 4

67 See also Lars H Gulbrandsen and Steinar Andresen, 'NGO Influence in the Implementation of the Kyoto Protocol: Compliance, Flexibility Mechanisms, and Sinks' (2004) 4(4) Global Envtl Pol 54.

68 Convention on International Trade in Endangered Species of Wild Fauna and Flora (adopted 3 March 1973, entered into force 1 July 1975) 993 UNTS 243.

69 van Asselt (n 59) 101ff. See also : Harro van Asselt and Thomas Hale, How Non-State Actors Can Contribute to More Effective Review Processes under the Paris Agreement (Stockholm Environment Institute 2016) 
sub-state actors in the context of voluntary initiatives. ${ }^{70}$ Not including a clear and strong role to NPS in the transparency framework would thus constitute an important 'missed opportunity' to facilitate the implementation of the new treaty and promote compliance with its terms. ${ }^{71}$

\section{Conclusion}

This article has provided an assessment of three key matters raised by the August $2018 \mathrm{draft}$ of the MPGs for the transparency framework of the Paris Agreement, in light of legal scholarship on transparency and recent submissions by Parties. First, I have argued that the multiplicity of anchors for a forwardlooking approach to transparency could be expanded over the course of the remaining negotiations. Requiring Parties to explain and justify the projected actions contained in their Improvement Plans may

70 Sander Chan and others, 'Reinvigorating International Climate Policy: A Comprehensive Framework for Effective Nonstate Action' (2015) 6(4) Glob Pol'y 466, 467. See also M Betsill and others, 'Building Productive Links between the UNFCCC and the Broader Climate Governance Landscape' (2015) 15 Global Envtl Pol 1 and Karin Bäckstrand and others, 'Non-State Actors in Global Climate Governance: From Copenhagen To Paris and Beyond' (2017) 26(4) Envtl Pol 561.

71 van Asselt (n 59) 108. See also Sébastien Duyck, 'MRV in the 2015 Climate Agreement: Promoting Compliance Through Transparency and the Participation of NGOs' (2014) 8(3) CCLR 175,

186 and Eric Dannenmaier, 'The Role of Non-state Actors in Climate Compliance' in Jutta Brunnée, Meinhard Doelle and Lavanya Rajamani (eds), Promoting Compliance in an Evolving Climate Regime (Cambridge University Press 2012).

72 Weiss and Jacobson (n 8) 545. contribute to build common understandings regarding the implementation of the new treaty, something which Brunnée and Hey have identified as a precondition for governance anchored in law.

Second, I have argued against excluding a consideration of barriers, successes and best practices in the attainment of individual NDCs from the scope of work of the transparency framework. Shining light both on reporting and on implementation efforts by Parties could nurture the sense that their initiatives will be met with reciprocity by other Parties and foster what Weiss and Jacobson have called a 'culture of compliance. $^{72}$ Lastly, I have highlighted the opportunity before the APA to design avenues for the formal involvement of NPS in the transparency framework. Their expertise, which flows from many sources including the transnational climate governance initiatives in which they could be also be involved, could significantly enrich the pursuit of the transparency framework's different goals.

The work that stands before Party negotiators under Agenda Item 5 for the short period between the Bangkok and Katowice negotiation sessions of the APA is considerable and extends far beyond the three issues that I have identified. Rather than seeing COP 24 as an 'all or nothing' moment for the Paris Rulebook, it may be helpful to envision the MPGs as part of an ongoing experiment with how and where to cast sunshine. Indeed, the periodic review of the transparency framework could be one way of continually improving its alignment with the goal of promoting Parties' accountability for the actions taken to implement the Paris Agreement. 